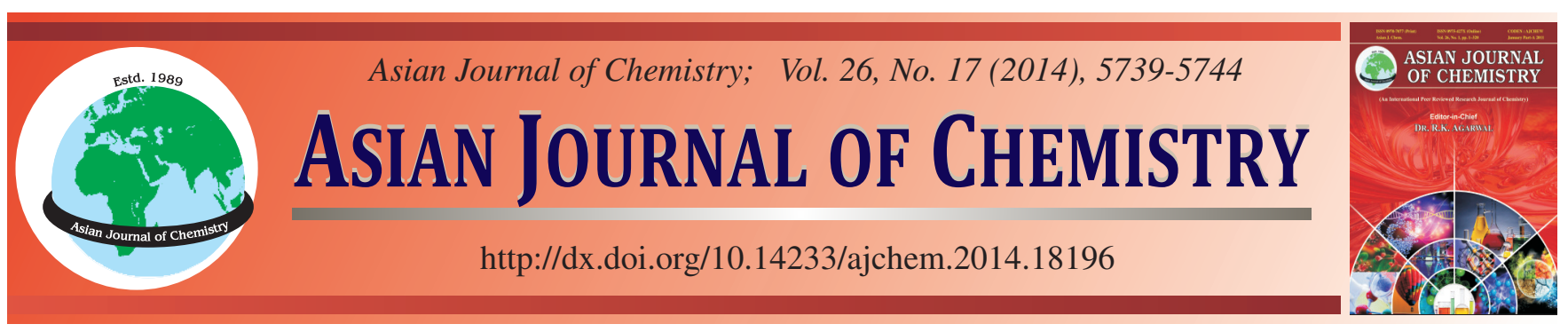

\title{
Differential Constitutive Relation for Creep of Large-Stone Porous Asphalt Mixture $\dagger$
}

\author{
BIN YANG ${ }^{1,2,3, *}$, SiHAO Mo ${ }^{1}$, LONGHUI $\mathrm{WANG}^{1}$ and $\mathrm{YE} \mathrm{JI}^{1}$
}

${ }^{1}$ College of Civil Engineering and Architecture, Guangxi University, Nanning, P.R. China

${ }^{2}$ Key Laboratory of Disaster Prevention and Structural Safety of Ministry of Education, Nanning, P.R. China

${ }^{3}$ Guangxi Key Laboratory of Disaster Prevention and Engineering Safety, Nanning, P.R. China

*Corresponding author: E-mail: yangbin5612@163.com

As a typical type of non-linear viscoelastic-plastic material, the large-stone porous asphalt mixture (LSPM) has very complex physical behaviour. Via connecting a Burgers model to viscoplastic material body in series, the viscoelastic-plastic constitutive equation was obtained. The viscoelastic-plastic constitutive model was then combined with the law of creep damage, which was used to describe the damage variation of the LSPM, to build the viscoelastic-plastic damage constitutive model. This resulting model can simulate the creep deformation behaviour of the LSPM relatively well. Moreover, the uniaxial compression creep tests on the LSPM were conducted in the MTS testing machine, through which the parameters for the viscoelastic-plastic damage constitutive model were determined. Finally, the approximate functions describing the relationships of the parameters versus temperature and stress were constructed.

Keywords: Differential constitutive relation, Creep, Asphalt mixture.

\section{INTRODUCTION}

Asphalt mixture is a typical type of viscoelastic-plastic polymer. Its mechanical behaviour is closely related to loading time, loading frequency and temperature. First, its mechanical behaviour is time-dependent. The history and process of the load and deformation decide the responses in stress or strain, which may exhibit such macro behaviour as obvious creep and stress relaxation. Second, it is related to the loading frequency. Many types of asphalt pavement distress are caused by fatigue damage. Third, since the temperature-sensitivity can lead to three different forms of asphalt mixture (elastomer, viscoelastic polymer, plastomer), respectively at low and high temperatures, the performance of asphalt pavement shall be checked in terms of its stability at high temperatures and crack resistance at low temperatures. Thus, asphalt mixture exhibits quite complex mechanical behaviour and its internal stress strain relationship can be reflected by the constitutive model. Many scholars have done a lot of research in this regard. At present, the constitutive relation for asphalt mixture is researched primarily with the following several methods: (1) Combining simple mechanical units to form a simplified mechanical model, using the model to express the mechanical properties of the material and finally establishing the diffe- rential constitutive equations to describe stress-strain-time relationship; (2) Employing integral constitutive relation according to the linear superposition principle; (3) Based on the irreversible thermodynamics theories, from the perspective of energy consumption, defining the internal variables and analyzing the thermomechanical characteristics so as to derive the differential equations describing the relationships between different physical quantities of the material; (4) Deriving the constitutive equations for asphalt mixture from the fundamentals of rational mechanics such as continuum mechanics and fracture mechanics. Since mechanical models are easily understood and utilized, they are employed by most scholars at home and abroad to express the constitutive relations for asphalt mixtures. Up to now, several scholars have conducted the following relevant studies:

Buttlar and Roqne ${ }^{1}$ obtained the internal mesostructural characteristics of asphalt mixture by using digital image processing technology, set up a model of the microstructure and mesostructure of the SMA asphalt mixture with the discrete element method and performed preliminary simulations of its mechanical properties. Dai and You ${ }^{2}$ scanned a cross section of the asphalt mixture specimens using a high-precision scanner, converted the mixture's internal characteristics into data in the discrete element software PFCZD for discrete-element 
modeling of its modulus and strength and conducted an indirect tensile test (IDT) at low temperature to verify the result of modeling. Through these processes, the response relationship between microstructure and macro properties was obtained. Kim and Buttlar ${ }^{3}$ set up the micromechanics-based damage model for asphalt mixture with the discrete element method and verified the result through a cantilever beam test. Hongxin et al..$^{4}$ deduced the energy dissipation expression incorporating damage evolution under cyclic stress, via introducing damage into the viscoelastic constitutive model for asphalt mixture in accordance with the hypothesis of strain equivalence and finally obtained the viscoelastic damage evolution equation. In 2008, based on a Burgers model, Shirong et al. ${ }^{5}$ built a discrete element model for homogeneous viscoelastic material using the principles of viscoelasticity and performed a numerical simulation of the creep process for the material. Jianlong et al. ${ }^{6}$ acquired the creep compliance curves at different temperatures through conducting the creep tests on asphalt joist at different temperatures with a bending beam rheometer (BBR) and then built the viscoelastic damage model for asphalt by coupling the model of continuum damage factors to the viscoelastic model based on the Burgers model.

A number of studies on the constitutive models for asphalt mixture have been done at the macroscopic or mesoscopic level by previous workers. However, these studies have generally focused on the small-stone or medium-stone ordinary asphalt mixtures made out of aggregates with nominal maximum sizes of below $19 \mathrm{~mm}$, seldom concerning the constitutive relation for large-stone porous asphalt mixture (LSPM). The LSPM and ordinary asphalt mixtures have greatly different mechanical properties and performance for pavement utilization and their constitutive models are totally different. The propagation path and speed of crack in them also show obvious differences. Given all the discrepancies, it's necessary to do in-depth research on the constitutive models for LSPM.

\section{Differential viscoelastic-plastic model}

Physical model: Asphalt mixture is a complex non-linear viscoelastic-plastic material. The deformation of the material is divided into such five types of deformation $e . g$., elastic deformation, viscous deformation, plastic deformation, viscoelastic deformation and viscoplastic deformation. Then its constitute equation can be derived from the combination of the appropriate models designed to describe the deformation of different parts. In this study, the deformation of asphalt mixture was divided into viscoelastic and viscoplastic deformations. While the viscoelastic component was described by a Burgers model, the viscoplastic component as represented by a viscoplastic body constituted by a Saint venant slider and a dashpot in parallel $^{7}$, as shown in Fig. 1.

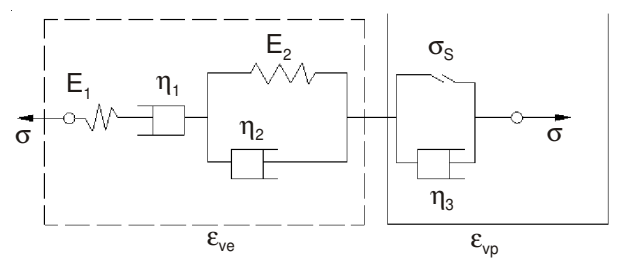

Fig. 1. Viscoelastic-plastic model
Viscoelastic deformation: Viscoelastic deformation was described by a Burgers model, which can be given as the following creep constitutive equation:

$$
\varepsilon_{\mathrm{ve}}(\mathrm{t})=\left[\frac{1}{\mathrm{E}_{1}}+\frac{1}{\eta_{1}} \mathrm{t}+\frac{1}{\mathrm{E}_{2}}\left(1-\mathrm{e}^{\left(-\mathrm{E}_{2} / \eta_{2}\right) \mathrm{t}}\right] \sigma_{0}\right.
$$

Viscoplastic deformation: Ronggui et al. ${ }^{8}$ believed that the stress was proportional to the acceleration of creep in a viscoplastic body and the dashpot in its physical model was a non-Newtonian fluid viscous damper. So the relationship between strain $\varepsilon_{\mathrm{vp}}$ and stress $\sigma_{\mathrm{vp}}$ can be represented by the following equation:

$$
\ddot{\varepsilon}_{\mathrm{vp}}=\frac{1}{\eta_{3}}\left\langle\sigma_{\mathrm{vp}}-\sigma_{\mathrm{s}}\right\rangle
$$

where, $\ddot{\varepsilon}_{\mathrm{vp}}$ is the acceleration of creep; $\eta_{3}$ is viscosity coefficient of the dashpot; $\sigma_{\mathrm{s}}$ is stress limit in the slider.

$$
\left\langle\sigma_{\mathrm{vp}}-\sigma_{\mathrm{s}}\right\rangle=\left\{\begin{array}{cc}
0 & \sigma_{\mathrm{vp}} \leq \sigma_{\mathrm{s}} \\
\sigma_{\mathrm{vp}}-\sigma_{\mathrm{s}} & \sigma_{\mathrm{vp}} \geq \sigma_{\mathrm{s}}
\end{array}\right.
$$

According to the deformation conditions, the deformation of specimen didn't occur when $t=0$. So the initial condition was:

$$
\varepsilon_{\mathrm{vp}} \mathrm{l}_{\mathrm{t}=0}=0
$$

Integrating Formula (2) and combining Formulas (2-4), the relationship between plastic strain and time can be given as:

$$
\varepsilon_{v p}(t)=\left\{\begin{array}{cc}
0 & \sigma_{v p} \leq \sigma_{s} \\
\frac{\sigma_{v p}-\sigma_{s}}{2 \eta_{3}} t^{2}-\text { At } & \sigma_{v p} \geq \sigma_{s}
\end{array}\right.
$$

If the applied stress $\sigma=\sigma_{0}$,

$$
\varepsilon_{v p}(t)=\left\{\begin{array}{cc}
0 & \sigma_{v p} \leq \sigma_{s} \\
\frac{\sigma_{0}-\sigma_{s}}{2 \eta_{3}} t^{2}-\text { At } & \sigma_{v p} \geq \sigma_{s}
\end{array}\right.
$$

The total deformation of the viscoelastic-plastic model includes the viscoelastic deformation $\varepsilon_{\mathrm{ve}}$ and viscoplastic deformation $\varepsilon_{\mathrm{vp}}$ :

$$
\varepsilon=\varepsilon_{\mathrm{ve}}+\varepsilon_{\mathrm{vp}}
$$

Then, the creep constitutive equation of the viscoelasticplastic model can be obtained via the combination of Formulas 1 and 6 :

$$
\left\{\begin{array}{c}
\varepsilon(\mathrm{t})=\left[\frac{1}{\mathrm{E}_{1}}+\frac{1}{\eta_{1}} \mathrm{t}+\frac{1}{\mathrm{E}_{2}}\left(1-\mathrm{e}^{\left(-\mathrm{E}_{2} / \eta_{2}\right) \mathrm{t}}\right)\right] \sigma_{0} \\
\varepsilon(\mathrm{t})=\left[\frac{1}{\mathrm{E}_{1}}+\frac{1}{\eta_{1}} \mathrm{t}+\frac{1}{\mathrm{E}_{2}}\left(1-\mathrm{e}^{\left(-\mathrm{E}_{2} / \eta_{2}\right) \mathrm{t}}\right)\right] \sigma_{0}+\frac{\sigma_{0}-\sigma_{\mathrm{s}}}{2 \eta_{3}} \mathrm{t}^{2}-\mathrm{At} \\
\sigma_{v p} \leq \sigma_{\mathrm{s}} \\
\sigma_{\mathrm{vp}} \geq \sigma_{\mathrm{s}}
\end{array}\right.
$$

Raw materials for the test: In the properties test on asphalt, the selected aggregate was the limestone from Wuming, 
Guangxi and the asphalt was TIPCO AH-70 asphalt. The test on the asphalt was carried out in accordance with the requirements and steps in Technical Specification for Construction of Highway Asphalt Pavements (JTP F40-2004) ${ }^{9}$ and Standard Test Methods of Bitumen and Bituminous Mixtures for Highway Engineering (JTG E20-2011) ${ }^{10}$ and yielded the fundamental asphalt property parameters as listed in Table- 1 .

\begin{tabular}{cccc}
\multicolumn{4}{c}{ TABLE-1 } \\
\multicolumn{4}{c}{ TEST RESULTS OF ASPHALT PROPERTIES } \\
\hline Parameters & Unit & Specification & Test results \\
\hline Penetration & $0.1 \mathrm{~mm}$ & $60-80$ & 75 \\
$\left(100 \mathrm{~g}, 25^{\circ} \mathrm{C}, 5 \mathrm{~s}\right)$ & & & \\
Penetration index (PI) & $\%$ & $\geq-0.8$ & -0.2 \\
$\quad \begin{array}{c}\text { Ductility } \\
\left(5^{\circ} \mathrm{C}, 5 \mathrm{~cm} / \mathrm{min}\right)\end{array}$ & $\mathrm{cm}$ & $\geq 100$ & 170 \\
$\begin{array}{c}\text { Softening point } \\
(\text { Ring \& Ball Method) }\end{array}$ & ${ }^{\circ} \mathrm{C}$ & $44-54$ & 50 \\
$\begin{array}{c}\text { Kinematic viscosity } \\
\left(135^{\circ} \mathrm{C}\right)\end{array}$ & $\mathrm{GPa} \cdot \mathrm{S}$ & $\leq 3.0$ & 1.201 \\
Density $\left(15^{\circ} \mathrm{C}\right)$ & $\mathrm{g} / \mathrm{cm}^{3}$ & Measurement & 1.034 \\
\hline
\end{tabular}

AM-25 was selected as the asphalt mixture, in which the proportions of mineral aggregate and asphalt were determined as per specifications for highway asphalt pavement ${ }^{11}$ (JTG D502006). The optimal asphalt-aggregate ratio was $3.1 \%$, the porosity was $12.9 \%$ and the size of the specimens was $\varnothing 100 \mathrm{~mm}$ $\times 100 \mathrm{~mm}$, as shown in Fig. 2 .

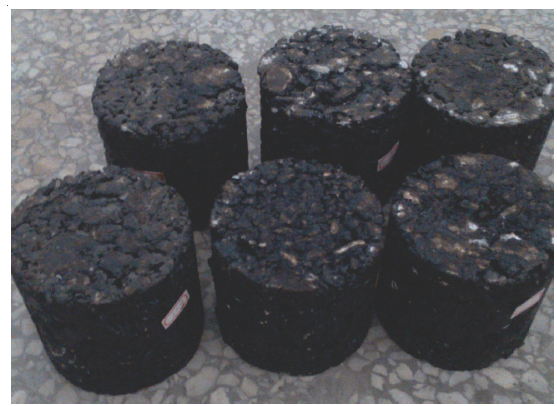

Fig. 2. Asphalt mixture specimens

Test methods: The constitutive relations for large-stone porous asphalt mixture were studied by the uniaxial compression creep tests, at a set temperature, a transient load was applied to the LSPM specimens and kept constant in order to measure the axial deformation versus time. Then the resulting creep curve was used to evaluate the characteristic of deformation of the asphalt mixture. The uniaxial compression creep test was performed on the specimens of $\varnothing 100 \mathrm{~mm} \times 100 \mathrm{~mm}$ (Fig. 3) in a MTS testing machine (Fig. 3). It followed the steps below: (1) applying a preload of $0.005 \mathrm{MPa}$ for $5 \mathrm{~min}$; (2) loading the specimen at the rate of $10 \mathrm{~mm} / \mathrm{min}$ until reaching the design load; (3) keeping the specimen under the constant load for $4000 \mathrm{~s}$ and (4) stopping loading. After several cycles, an average stress limit $\sigma_{\mathrm{s}}$ was yielded: $\sigma_{\mathrm{s}}=0.05 \mathrm{MPa}$.

Evaluation indicators: The creep strain was taken as the evaluation indicator of the characteristics of creep and it can be calculated by the following formula:

$$
\varepsilon=\frac{\Delta \mathrm{h}}{\mathrm{h}_{0}}
$$

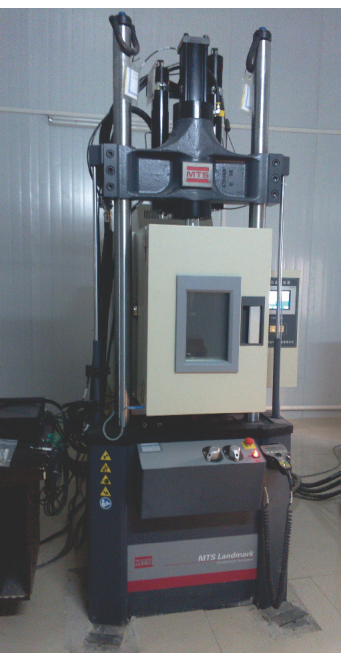

Fig. 3. MTS testing system

where $\Delta \mathrm{h}$ is the compression height, also known as the change in the specimen height $(\mathrm{mm}) ; \mathrm{h}_{0}$ is the original specimen height (mm).

Slider biggest stress $\sigma_{\mathrm{s}}$ was determined by constant strain rate compression tests, its value is $\sigma_{\mathrm{s}}=0.05 \mathrm{MPa}$, other six parameters for the model were determined via fitting curves to the test data. Fig. 4 shows that the fitted curves of the viscoelastic-plastic constitutive model have a relatively good fit to the test data. In the early stage, the fitted curves exhibit small deviation and high precision. In the late stage when the creep accelerated, by contrast, the curves show an increasing deviation, but still approximately fit the test data curves in general.

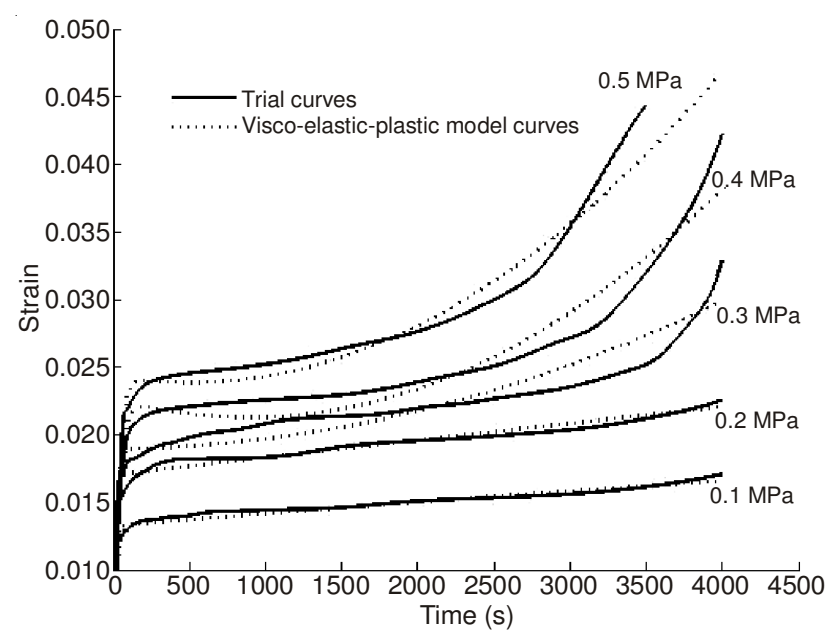

Fig. 4. Fitting of the viscoelastic-plastic constitutive model

Viscoelastic-plastic damage model: Asphalt mixture is a type of non-continuum. During its formation, the irregularity of aggregate and restrictive construction technologies inevitably result in some voids and cracks, which are considered as the initial damage in asphalt mixture. The occurrence of the damage breaks up the overall continuity and reduces the rigidity of the material. The LSPM, with a porosity of between 12 and $18 \%$, usually undergoes heavier initial damage than ordinary asphalt mixtures. So the damage is a significant element to consider in the design of the constitutive model. 
Description of damage: Damage mechanics is a discipline to illustrate the evolution of deformation and damage in materials under specific loading and environmental conditions. It has been applied initially to metal materials and then gradually to such other fields as biological materials, composite materials and concrete, but has seldom been used in research on the damage in asphalt mixtures ${ }^{12}$.

According to Shouwen and Xiqiao ${ }^{13}$ that the reduction in loading area of material is the main cause of degradation of materials. So the continuity $\varphi$ can be used to describe the damage in a material and Formula 10 is obtained as follows:

$$
\varphi=\frac{\tilde{\mathrm{A}}}{\mathrm{A}}
$$

where, $\tilde{\mathrm{A}}$ is the loading area of the material undergoing damage and $\mathrm{A}$ is the effective area of the material in the undamaged state.

The idea of damage factor $\mathrm{D}$ was introduced by Rabotnov:

$$
\mathrm{D}=1-\varphi
$$

Then the expression of the effective stress $\tilde{\sigma}$ was obtained:

$$
\widetilde{\sigma}=\frac{F}{\tilde{A}}=\frac{\sigma_{0}}{1-D}
$$

where $\sigma_{0}$ is the stress (Cauchy stress) in the material in the undamaged state.

To use continuum damage mechanics in the research on the creep damage in LSPM, it is necessary to define an appropriate damage parameter. Using Norton's theorem, Kachanov obtained his Kachanov's law of creep damage:

$$
\dot{\mathrm{D}}=\mathrm{C}^{v}(1-\mathrm{D})^{-v}
$$

where $\mathrm{C}$ and $\mathrm{K}$ are the material constants, usually determined by experiments.

Formula (13) was integrated:

$$
\mathrm{t}=\frac{1}{\mathrm{~K}}\left[1-(1-\mathrm{D})^{\mathrm{K}+1}\right]\left(\frac{\sigma}{\mathrm{C}}\right)^{-\mathrm{K}}
$$

If the material was experiencing damage during the period of $t=t_{r}$ with $D=1$, the following formula was obtained:

$$
\mathrm{t}_{\mathrm{r}}=\frac{1}{\mathrm{~K}+1}\left(\frac{\sigma}{\mathrm{C}}\right)^{-\mathrm{K}}
$$

From Formulae (14) and (15), the following formula was derived:

$$
\mathrm{D}=1-\left(1-\frac{\mathrm{t}}{\mathrm{t}_{\mathrm{r}}}\right)^{\frac{1}{\mathrm{~K}+1}}
$$

where $t_{r}$ is the time threshold of creep damage, $\mathrm{K}$ is a material constant.

The coupling method is usually employed to investigate the behaviour of materials in damage mechanics, which means that the damage constitutive model has the same form as the constitutive model without damage, except for the replacement of the Cauchy stress by the effective stress $\tilde{\sigma}$. So via the importing of Formula (16) to Formulae (12) and (8), the viscoelastic-plastic damage constitutive equation for LSPM was output:

$$
\begin{array}{r}
\varepsilon(t)=\left[\frac{1}{E_{1}}+\frac{1}{\eta_{1}} t+\frac{1}{E_{2}}\left(1-e^{\left(-E_{2} / \eta_{2}\right) t}\right] \sigma_{0}\left(1-\frac{t}{t r}\right)^{H}\right. \\
+\frac{\sigma_{0}(1-t / t r)^{H}-\sigma_{s}}{2 \eta_{3}} t^{2}-a t
\end{array}
$$

where

$$
\mathrm{H}=\frac{1}{\mathrm{~K}+1}
$$

Parameters fitting: From previous studies, it is concluded that the characteristics of creep of asphalt mixture was affected by the stress intensity ${ }^{14}$. While the load of 0.1-0.7 MPa was used in most of these studies ${ }^{15}$, five different stresses $(\sigma=0.1$, $0.2,0.3,0.4,0.5 \mathrm{MPa}$ ) were used in the compression creep test on the specimens in this study. The test results were represented by the following creep curves (Fig. 5):

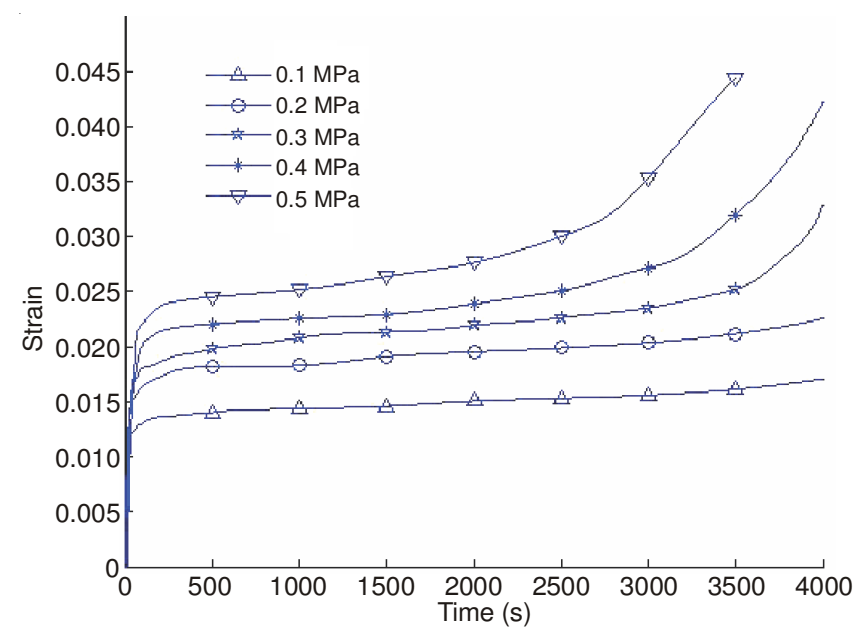

Fig. 5. Creep curves under different stresses $\left(\mathrm{T}=40^{\circ} \mathrm{C}\right)$

The viscoelastic-plastic damage constitutive model (Table-2) was obtained through fitting the test data in Fig. 5. The correlation coefficients in Table-2 are all larger than 0.99, indicating a high accuracy of the fitting. The comparisons between the estimations and measurements of the model parameters were displayed in Fig. 6.

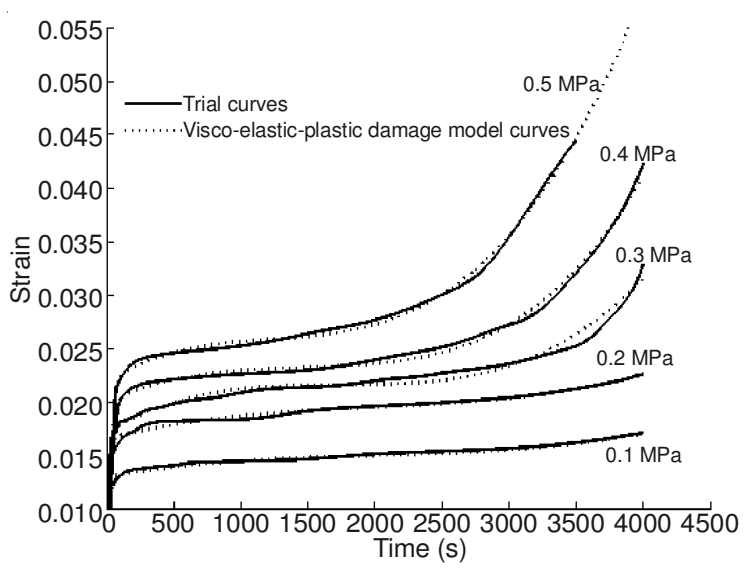

Fig. 6. Fitting of the viscoelastic-plastic damage constitutive model

As shown in Fig. 6, the viscoelastic-plastic damage constitutive model fits the creep deformation of LSPM relatively well, so the model has a high accuracy of fitting. 


\begin{tabular}{cccccc}
\hline \multicolumn{5}{c}{ TABLE-2 } & \\
\multicolumn{1}{c}{ FITTING RESULTS OF THE PARAMETERS FOR THE VISCOELASTIC-PLASTIC DAMAGE CONSTITUTIVE MODEL } \\
\hline Strain $(\mathrm{MPa})$ & 0.1 & 022 & 0.3 & 0.4 & 0.5 \\
$\mathrm{E}_{1}(\mathrm{MPa})$ & -1.1758 & 66168.47 & -36.1784 & -28.2411 & -0.4319 \\
$\mathrm{E}_{2}(\mathrm{MPa})$ & 1.0210 & 12.1786 & 11.817 & 11.7601 & -0.9755 \\
$\mathrm{~h}_{1}(\mathrm{GPa} \cdot \mathrm{S})$ & 0.6786 & 4.2602 & -1.0704 & 4.5921 & 5.3756 \\
$\mathrm{~h}_{2}(\mathrm{GPa} \cdot \mathrm{S})$ & 6.2358 & 177.1019 & 155.1462 & 269.8638 & 540.23 \\
$\mathrm{~h}_{3} / 10^{5}(\mathrm{GPa} \cdot \mathrm{S})$ & 4.7599 & -4.9617 & 1.9609 & 3.5191 & 5717.5222 \\
$\mathrm{t}_{\mathrm{r}} / 10^{5}(\mathrm{GPa} \cdot \mathrm{S})$ & -1.3048 & 1.0945 & 16.5644 & -0.8517 & $-0.2405 \times 10^{-5}$ \\
$\mathrm{H}$ & -0.0474 & -0.3484 & -3.793 & -0.4907 & -0.9851 \\
$\mathrm{~A}$ & 0.1473 & 0.0469 & -0.2802 & 0.087 & $1.8371 \times 10^{-7}$ \\
$\mathrm{Coefficient}$ & 0.9915 & 0.9976 & 0.9966 & 0.999 & 0.9969 \\
\hline
\end{tabular}

Parameters analysis: In most areas of China, the maximum temperature in summer ranges between 35 and $40{ }^{\circ} \mathrm{C}$ and the asphalt pavement temperature, usually $20^{\circ} \mathrm{C}$ higher than the air temperature, can reach about $60^{\circ} \mathrm{C}$. This study focused on the LSPM which is usually used for the asphalt overlay as a crack-relief layer between the asphalt surface layer and cement concrete slab. Since heat loss occurs during the heat transfer down through the pavement, the temperature of the crack-relief layer is normally about $50{ }^{\circ} \mathrm{C}$. Given the climatic conditions of Guangxi Province and the creep characteristics of asphalt mixture at low temperature, the temperature range of $10-50{ }^{\circ} \mathrm{C}$ was chosen for the creep test on asphalt mixture.

In this study, the compression creep tests were conducted on the asphalt mixture under axial stresses of 0.1-0.5 MPa. Via the tests at different temperatures and under different stresses, the viscoelastic-plastic damage constitutive model was researched and the relationships between each model parameter and the temperature and stress were analyzed. The compression creep test method was as follows:

Test I: At a constant temperature T of $40^{\circ} \mathrm{C}$, conducting the compression creep test on the specimens under the stresses $\sigma$ of $0.1,0.2,0.3,0.4$ and $0.5 \mathrm{MPa}$, respectively.

Test II: Conducting the compression creep test on the specimens under a constant stress $\sigma$ of $0.3 \mathrm{MPa}$ at different temperatures $\mathrm{T}$ of $20,30,40,50$ and $60^{\circ} \mathrm{C}$, respectively.

Assuming that each model parameter can be plotted as a function of temperature and stress, according to the relationships between the parameters and the temperature and stress, the approximate functions describing these relationships can be obtained via 3D fitting with the help of the software 1stOpt. These functions were defined by the following rational (fractional) expressions:

$$
\begin{gathered}
\mathrm{E}_{1}(\mathrm{~T}, \sigma) \\
=\frac{\left(-0.2670 \mathrm{~T}^{2}-722.5762 \sigma^{2}+40.8571 \mathrm{~T} \sigma+120.1500\right)}{(0.0001 \mathrm{~T}-0.0086 \sigma-0.0024)} \\
\mathrm{E}_{2}(\mathrm{~T}, \sigma)=\frac{\left(-0.0032 \mathrm{~T}^{2}-167.5122 \sigma^{2}+2.4524 \mathrm{~T} \sigma-2.3569\right)}{(0.0347 \mathrm{~T}-0.1509 \sigma-0.8845)}
\end{gathered}
$$

$$
\begin{aligned}
& \eta_{1}(\mathrm{~T}, \sigma) \\
& =\frac{\left(248.0890 \mathrm{~T}^{2}+1.4368 \sigma^{2}-2.2789 \mathrm{~T} \sigma+1.5055 \times 10^{6}\right)}{(0.0012 \mathrm{~T}-0.2053 \sigma-0.0026)}
\end{aligned}
$$

$\eta_{2}(\mathrm{~T}, \sigma)$

$=\frac{\left(63.020 \mathrm{~T}^{2}+1.2550 \times 10^{6} \sigma^{2}-1.4062 \times 10^{4} \mathrm{~T} \sigma-7.2133 \times 10^{4}\right)}{\left(-2.9347 \mathrm{~T}+9.4505 \times 10^{2} \sigma-2.4340 \times 10^{2}\right)}$

$\eta_{3}(\mathrm{~T}, \sigma)$

$=\frac{\left(3.2435 \mathrm{~T}^{2}+293789.5181 \sigma^{2}-731.2963 \mathrm{~T} \sigma-22915.5029\right)}{(-0.0015 \mathrm{~T}-17.2162 \sigma+5.2421)}$

$\mathrm{t}_{\mathrm{r}}(\mathrm{T}, \sigma)$

$=\frac{\left(-0.2709 \mathrm{~T}^{2}-3544.0812 \sigma^{2}+56.3901 \mathrm{~T} \sigma+150.4322\right)}{(-0.9374 \mathrm{~T}-489.8123 \sigma+188.9270)}$

$\mathrm{H}(\mathrm{T}, \sigma)$

$=\frac{\left(1.2540 \times 10^{-8} \mathrm{~T}^{2}+0.0002 \sigma^{2}-3.3356 \times 10^{-6} \mathrm{~T} \sigma-1.0897 \times 10^{-5}\right)}{\left(4.0996 \times 10^{-8} \mathrm{~T}-9.9672 \times 10^{-5} \sigma-3.0379 \times 10^{-5}\right)}$

$\mathrm{A}(\mathrm{T}, \sigma)$

$=\frac{\left(5.3922 \mathrm{~T}^{2}+64492.2753 \sigma^{2}-1158.9935 \mathrm{~T} \sigma-1608.1027\right)}{(727.3615 \mathrm{~T}-142771.2857 \sigma+17698.9745)}$ $(727.3615 \mathrm{~T}-142771.2857 \sigma+17698.9745)$

Verification of model: The stress and temperature were imported to formulae 18-25 and then to the viscoelastic-plastic damage constitutive equation Formula (17) to yield the estimations under different conditions. According to the comparisons with the measurements, as shown in Figs. 7 and 8, the model curves exhibit a good fit to the test data curves. This demonstrates that the proposed viscoelastic-plastic damage constitutive model is relatively capable of accurately describing the creep behaviour of LSPM.

\section{Conclusion}

Via the connection of a Burgers model to viscoplastic material body in series, the viscoelastic-plastic constitutive equation was obtained. Then after the fitting and comparison, the viscoelastic-plastic constitutive model proved to be capable of accurately describing the creep behaviour of the asphalt mixture. Kachanov's law of creep damage, which was employed to describe the damage variation of the LSPM, was combined with the viscoelastic-plastic constitutive model to yield the viscoelastic-plastic damage constitutive model. The model obtained can simulate the creep deformation of the LSPM 


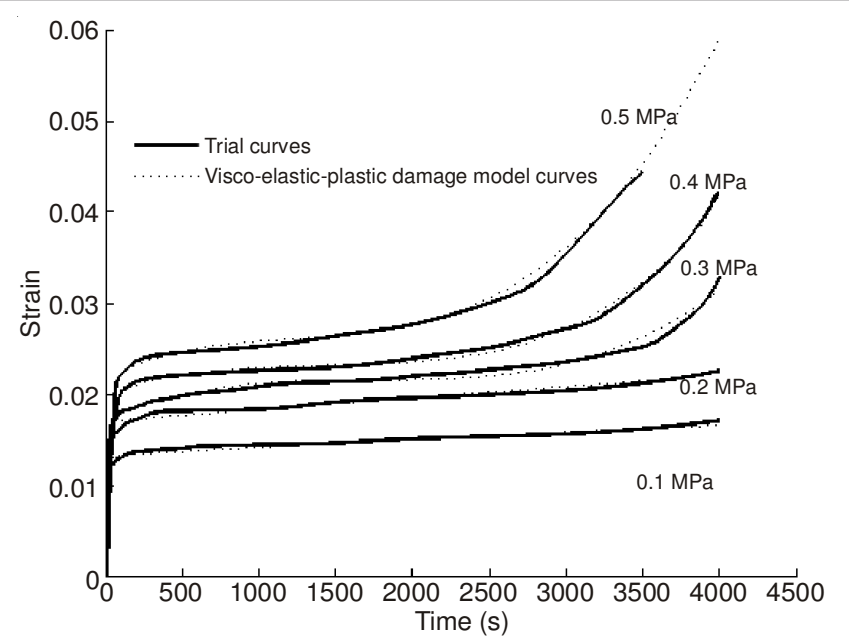

Fig. 7. Verification of the viscoelastic-plastic damage model under different stresses

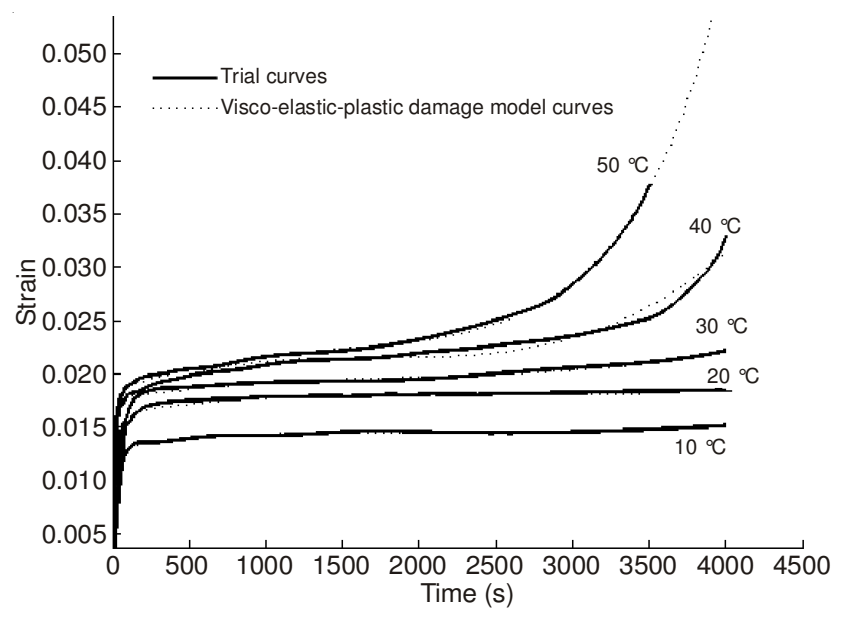

Fig. 8. Verification of the viscoelastic-plastic damage model at different temperatures

relatively well, indicating a high accuracy of fitting. Through the parameter analysis for the viscoelastic-plastic damage model, the approximate functions describing the relationships of the parameters versus temperature and stress were constructed.

\section{ACKNOWLEDGEMENTS}

The project was supported by National Natural Science Foundation of China $(51168005,51268003)$, Key Project of Guangxi Scientific Research and Technological Development Plan (10124006-10), Key Project of Guangxi Science and Technology Lab Center (LGZX201107), Natural Science Foundation of Guangxi (2012GXNSFAA053205), Foundation Project of Key Laboratory of Disaster Prevention and Engineering Safety of Guangxi (2012ZDX08).

\section{REFERENCES}

1. W.G. Buttlar and R. Roque, Micromechanical modeling to predict the stiffness of asphalt concrete: Fifth Pan American Congress on Applied Mechanics, Applied Mechanics in the Americas, San Juan, Puerto Rico, Godoy, (1997).

2. Q. Dai and Z. You, J. Eng. Mech., 133, 163 (2007).

3. H. Kim and W.G. Buttlar, Micro Mechanical Fracture Modeling of Asphalt Mixture using the discrete Element Method, Geotechnical Special Publication, vol. 130-142, pp. 209-223 (2005).

4. G. Hongxin, Z. Jianlong and Z. Qisen, Mech. Eng., 29, 50 (2007).

5. S.R. Feng, X.G. Hu and Y. Liu, J. Highway Transportation Res. Develop., 2, 12 (2008).

6. Z. Jianlong, L. Songtao and T. Xiaoge, Eng. Mechanics, 25, 193 (2008).

7. Y. Tingqing, Theory and Applications of Viscoelasticity, Science Press, Beijing (2004).

8. D. Ronggui, Z. Depei, Z. Zhuoyuan, Chinese J. Rock Mechanics Eng., 06, 780 (2001).

9. Technical Specification for Construction of Highway Asphalt Pavements (JTG F40-2004), China Communications Press, Beijing (2004).

10. Standard Test Methods of Bitumen and Bituminous Mixtures for Highway Engineering (JTG E20-2011), China Communications Press, Beijing (2011).

11. Specifications for Highway Asphalt Pavement (JTGD50-2006), China Communications Press, Beijing (2006).

12. G.W. Zeng, X.H. Yang and A.Y. Yin, J. Wuhan Univ. Sci. Technol., 05, 364 (2011)

13. S.W. Yu and X.Q. Feng, Damage Mechanics, Tsinghua University Press (1997).

14. Y. Yong, Experimental Research on Viscoelastic-Plastic Constitutive Model for Asphalt Mixture, Huazhong University of Science and Technology (2009).

15. Q. Feng, Evaluation of the High-Temperature Stability of Asphalt Mixture Based on Creep Test, Chang'an University (2009). 